Electronic Supplementary Information

\title{
Trichloromethanesulfonyl chloride: a chlorinating reagent for aldehydes
}

Ciril Jimeno, ${ }^{a}$ Lidong $\mathrm{Cao}^{b}$ and Philippe Renaud ${ }^{b^{*}}$

a) Department of Biological Chemistry and Molecular Modelling. IQAC-CSIC. c/Jordi Girona 18-24. E08034 Barcelona, Spain.

b) Department of Chemistry and Biochemistry, University of Bern, Freiestrasse 3, 3012 Bern, Switzerland.

E-mail: philippe.renaud@dcb.unibe.ch

\section{Table of Contents}

1. Preparation of 3a without purification 2

2. Determination of the enantiomeric excess of compounds $3 a$ and $3 b$

(S)-2-Chloro-1-octanol (S)-3b.

(S)-2-Chloro-3-phenyl-1-propanol (S)-3a 5

3. NMR Spectra of $3 a-3 g$ and $2 h-2 j \quad 8$

${ }^{1} H-N M R$ spectra of $3 a$

${ }^{13} \mathrm{C}-\mathrm{NMR}$ spectra of $\mathbf{3 a}$

${ }^{1} \mathrm{H}-\mathrm{NMR}$ spectra of $\mathbf{3} \boldsymbol{b}$

${ }^{13} C-N M R$ spectra of $\mathbf{3 b}$

${ }^{1} \mathrm{H}-\mathrm{NMR}$ spectra of $3 \mathrm{c}$

${ }^{13} \mathrm{C}-N M R$ spectra of $3 \mathrm{c}$

${ }^{1} \mathrm{H}-\mathrm{NMR}$ spectra of $\mathbf{3 d}$

${ }^{13} C-N M R$ spectra of $\mathbf{3 d}$

${ }^{1} \mathrm{H}-\mathrm{NMR}$ spectra of $3 \boldsymbol{e}$

${ }^{13} C-N M R$ spectra of $3 e$

${ }^{1} \mathrm{H}-\mathrm{NMR}$ spectra of $\mathbf{3} \boldsymbol{f}$

${ }^{13} C-N M R$ spectra of $3 f$

${ }^{1} \mathrm{H}-\mathrm{NMR}$ spectra of $\mathbf{3 g}$

${ }^{13} \mathrm{C}-\mathrm{NMR}$ spectra of $\mathbf{3 g}$

${ }^{1} \mathrm{H}-\mathrm{NMR}$ spectra of $\mathbf{2 h}$

${ }^{13} \mathrm{C}-\mathrm{NMR}$ spectra of $\mathbf{2 h}$

${ }^{1} \mathrm{H}-\mathrm{NMR}$ spectra of $\mathbf{2} \boldsymbol{i}$

${ }^{13} \mathrm{C}-N M R$ spectra of $\mathbf{2} \boldsymbol{i}$

${ }^{1} \mathrm{H}-N M R$ spectra of $\mathbf{2} \boldsymbol{j}$

${ }^{13} \mathrm{C}-\mathrm{NMR}$ spectra of $\mathbf{2} \boldsymbol{j}$ 


\section{Preparation of 3a with acid washing/filtration}

General procedure A was followed starting from 1a (130 $\mu \mathrm{L}, 1 \mathrm{mmol})$. After $\mathrm{NaBH}_{4}$ reduction, water $(5 \mathrm{~mL})$ and $\mathrm{Et}_{2} \mathrm{O}(10 \mathrm{~mL})$ were added. The organic layer was washed with $1 \mathrm{M} \mathrm{HCl}(5 \times 2 \mathrm{~mL})$, brine $(1 \times 2 \mathrm{~mL})$, and dried over $\mathrm{Na}_{2} \mathrm{SO}_{4}$. Solvents were evaporated to afford crude $3 a(185 \mathrm{mg})$. Purification of the crude product by flash filtration through silica gel (pentane/TBME) afforded 3a (160 mg, 94\%).

After acid washing

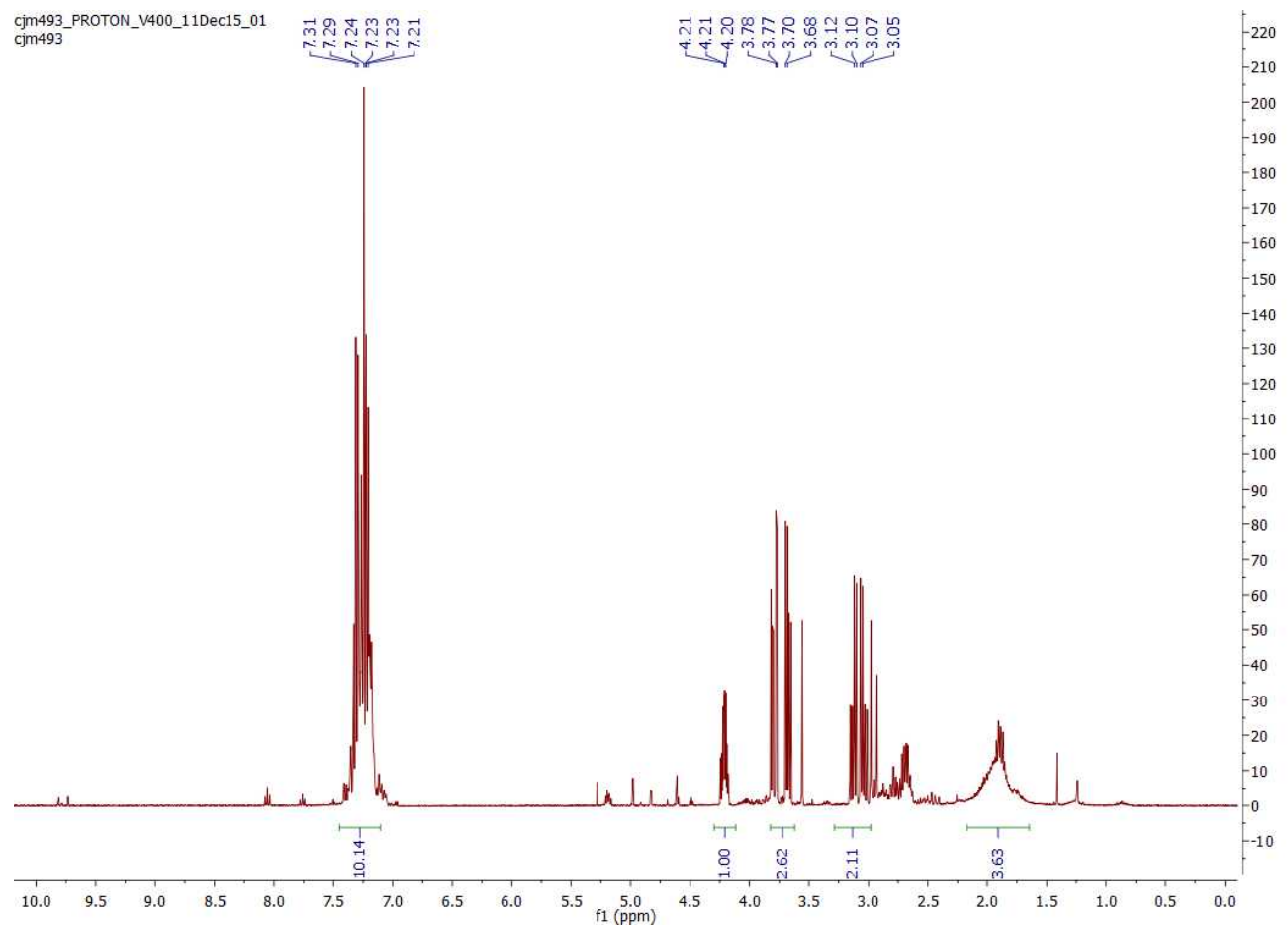

After flash filtration through silica gel

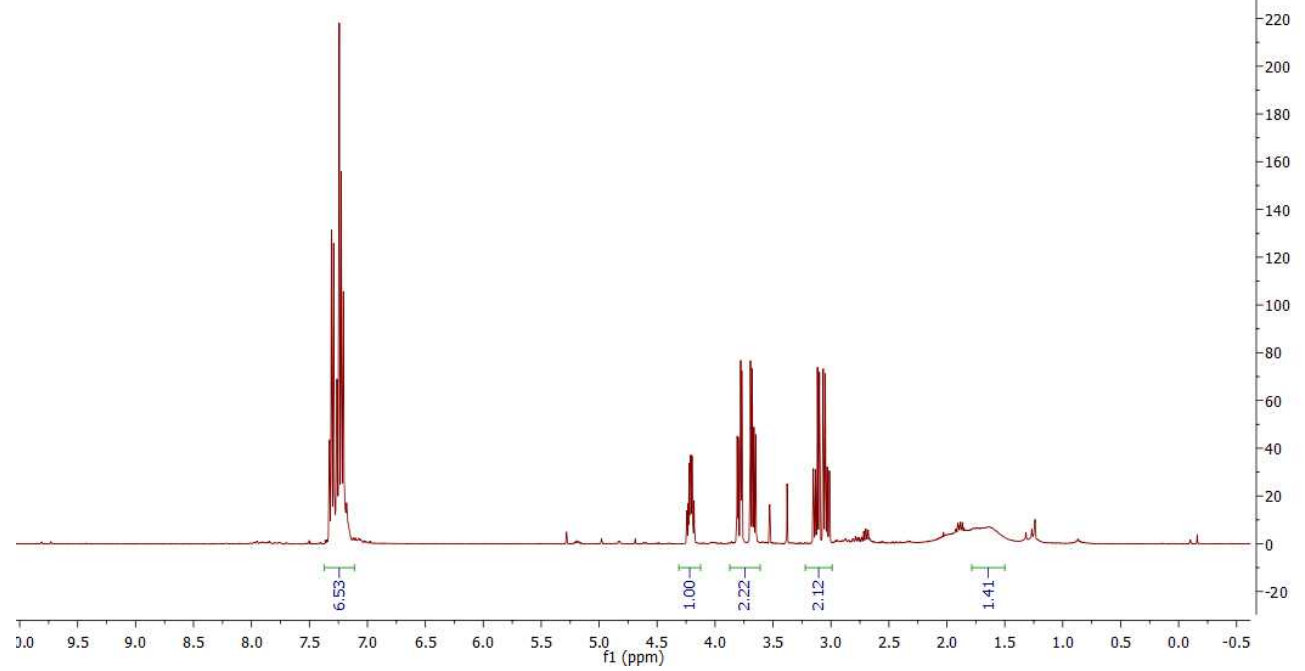


2. Determination of the enantiomeric excess of compounds $3 a$ and $3 b$

(S)-2-Chloro-1-octanol (S)-3b.

${ }^{1} \mathrm{H}-\mathrm{NMR}$ :

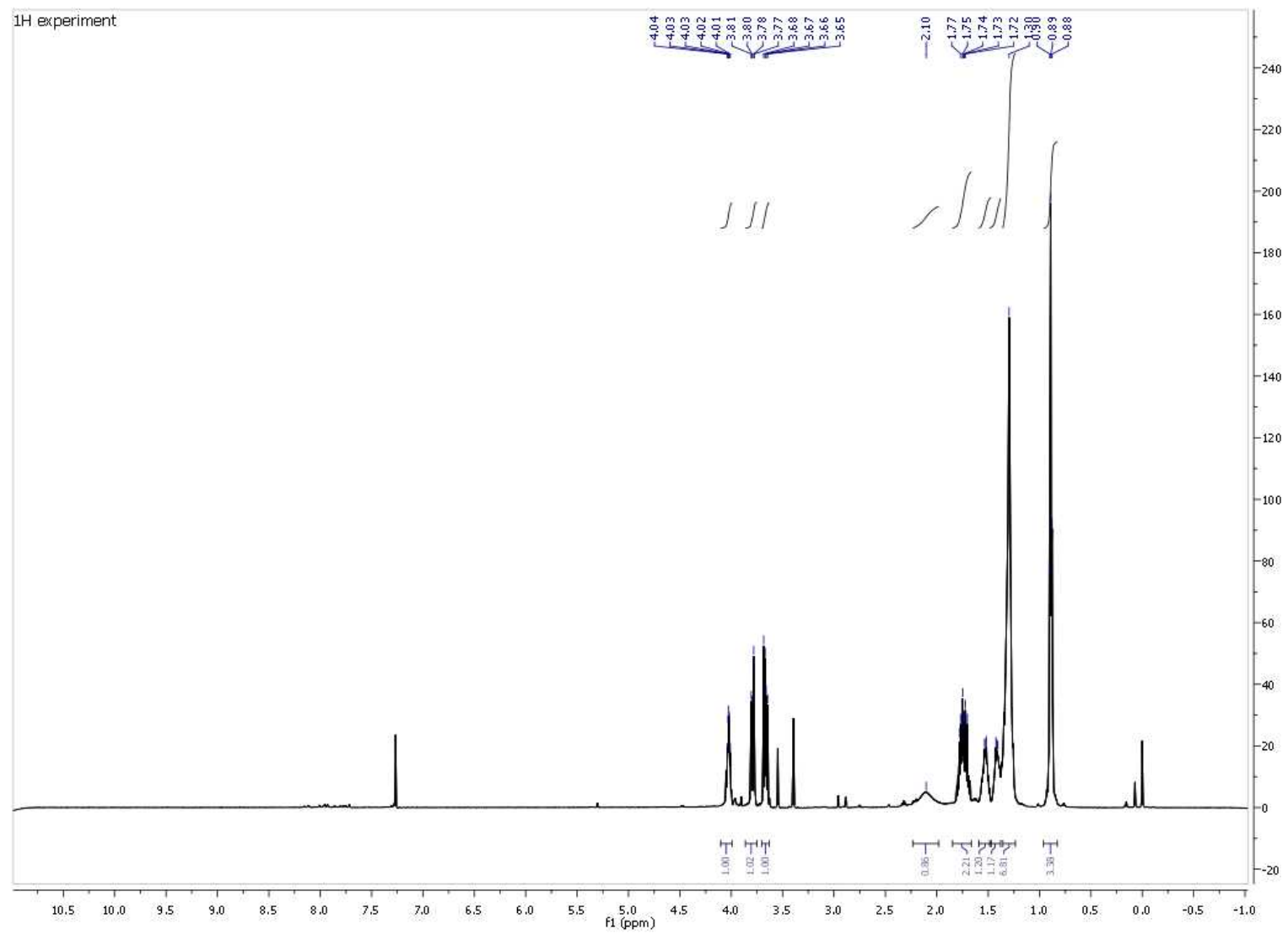

$[\alpha]_{\mathrm{D}}^{25}=-36.7\left(\mathrm{c}=1.4, \mathrm{CH}_{2} \mathrm{Cl}_{2}, 93 \% \mathrm{ee}\right)$, which corresponds to $(\mathrm{S})$ configuration. ${ }^{1}$

Lit. $[\alpha]_{D}^{25}=-25.30\left(\mathrm{c}=1.0, \mathrm{CHCl}_{3}, 96 \%\right.$ ee) (M. Amatore, T. D. Beeson, S. P. Brown, D. W. C. MacMillan, Angew. Chem. Int. Ed. 2009, 48, 5121-5124). 
Determination of enantioselective excess by GC analyses were performed with an Agilent $6890 \mathrm{~N}$ chromatograph with autosampler and FID detector, using a Chiraldex Tau column, at $90^{\circ} \mathrm{C}$ isothermal.

GC analysis of the racemic mixture

Column Chiraldex $30 \mathrm{~m} \times 0.25 \mathrm{~mm}, 0.25 \mu \mathrm{m}$

Tinj-aux $170^{\circ} \mathrm{C}$

$1.5 \mathrm{~mL} / \mathrm{min}$

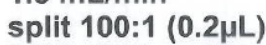

$90^{\circ} \mathrm{C}$, SIM mode

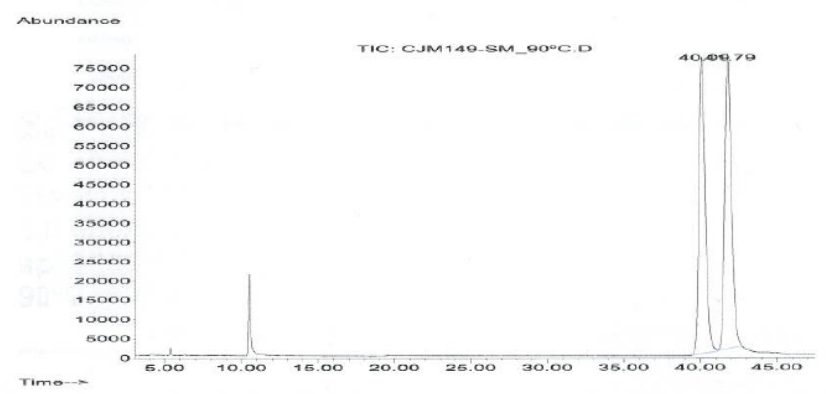

peak R.T. first max last PK peak corr. corr. \% of
\# min scan scan scan TY height area \% max. total

$170.090511452495397 \quad$ M3 $76756 \quad 2238744993.42 \% 48.299 \%$

241.789540054905618 M4 $7650523964763 \quad 100.00 \% 51.701 \%$

GC analysis of the enantiomerically enriched product

$1.5 \mathrm{~mL} / \mathrm{min}$

split 100:1 $(0.2 \mu \mathrm{L})$

$90^{\circ} \mathrm{C}$, SIM mode

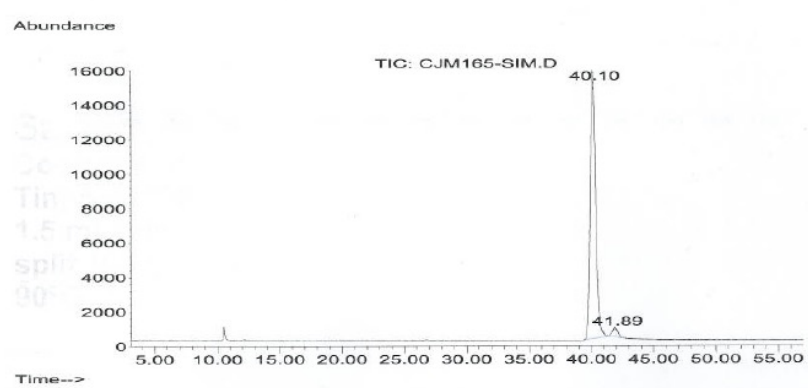

peak R.T. first max last PK peak corr. corr. \% of

\# $\min$ scan scan scan TY height area \% max. total

140.102514852525432 M2 $15616 \quad 4675486100.00 \% 96.665 \%$

$241.886543255055646 \quad$ M3 $529 \quad 161328 \quad 3.45 \% \quad 3.335 \%$ 
(S)-2-Chloro-3-phenyl-1-propanol (S)-3a

\section{${ }^{1} \mathrm{H}-\mathrm{NMR}$}

cjm494-flashed_PROTON_V400_22Dect5
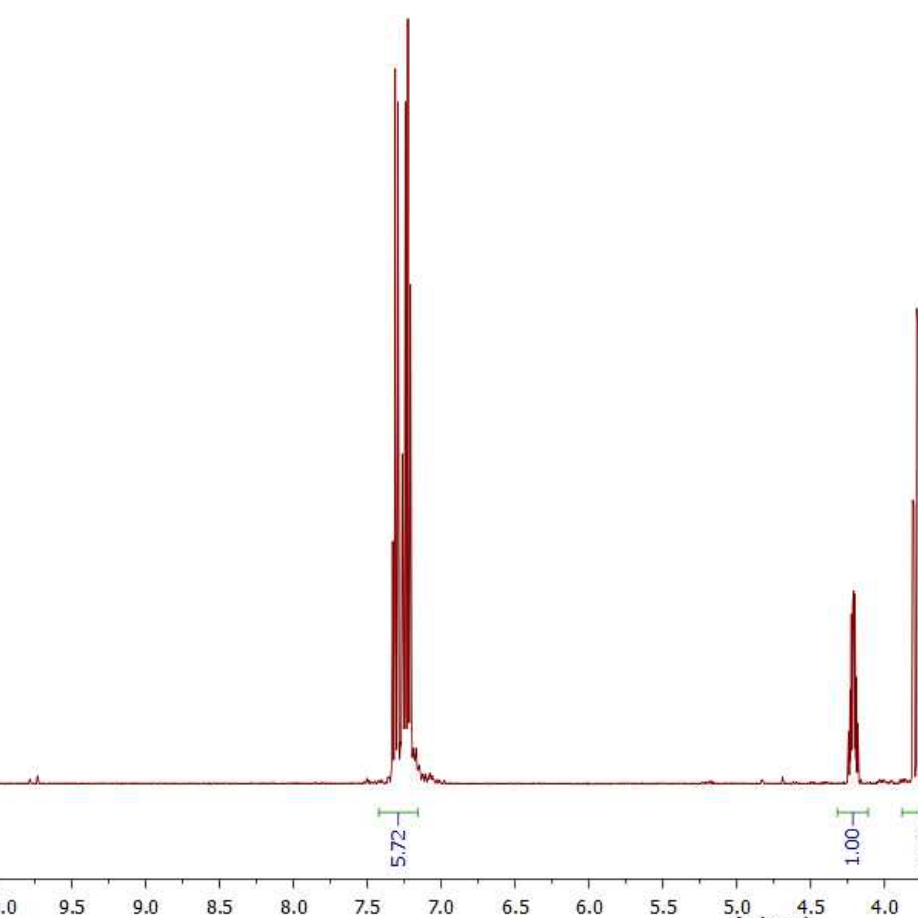

$[\alpha]_{D}^{25}=-18.2\left(\mathrm{c}=1.0, \mathrm{CH}_{2} \mathrm{Cl}_{2}, 81 \%\right.$ ee), which corresponds to $(S)$ configuration.

Lit. $[\alpha]_{D}^{25}=-21.67\left(\mathrm{c}=1.0, \mathrm{CHCl}_{3}, 95 \%\right.$ ee) (M. Amatore, T. D. Beeson, S. P. Brown, D. W. C. MacMillan, Angew. Chem. Int. Ed. 2009, 48, 5121-5124) 
Determination of enantiomeric excesses by HPLC analyses was performed on the $p$-nitrobenzoate derivative using a Chiralcel IA column and guard column, with a 90:10 mixture of hexanes/isopropanol at $0.9 \mathrm{ml} / \mathrm{min}$ flow.

Preparation of the $p$-nitrobenzoate derivative of 3a: A sample of (S)-3a (65 mg, $0.381 \mathrm{mmol}$ ) was dissolved in dry $\mathrm{CH}_{2} \mathrm{Cl}_{2}(2 \mathrm{ml})$ and treated with $p$-nitrobenzoyl chloride $(0.952 \mathrm{mmol}, 177 \mathrm{mg})$, triethylamine $(1.5$ $\mathrm{mmol}, 210 \mu \mathrm{l})$, and DMAP $(0.082 \mathrm{mmol}, 10 \mathrm{mg})$. The reaction was left reacting for $6 \mathrm{~h}$ at $\mathrm{rt}$, then quenched with water and diluted with ether. The organic layer was washed with $1 \mathrm{M} \mathrm{HCl}(3 \times)$, dried with $\mathrm{MgSO}_{4}$ and evaporated. The residue was purified by flash chromatography eluting with hexane/ethyl acetate mixtures of increasing polarity.

HPLC of the racemic mixture
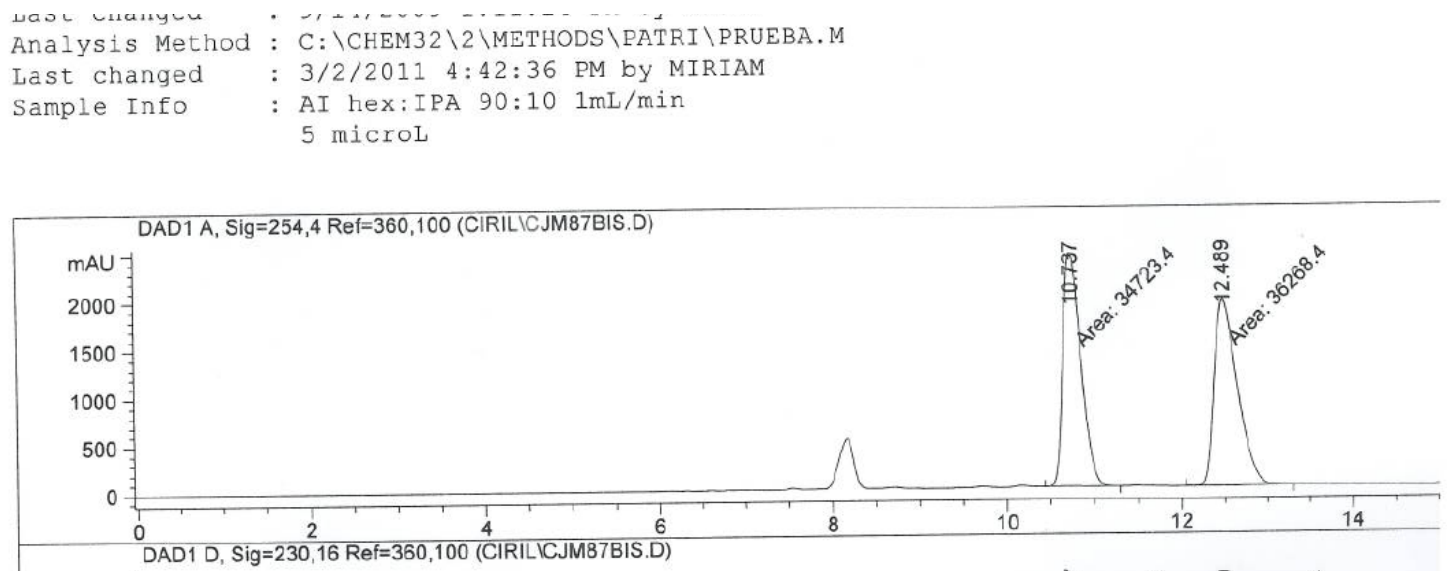

HPLC of the enantiomerically enriched compound
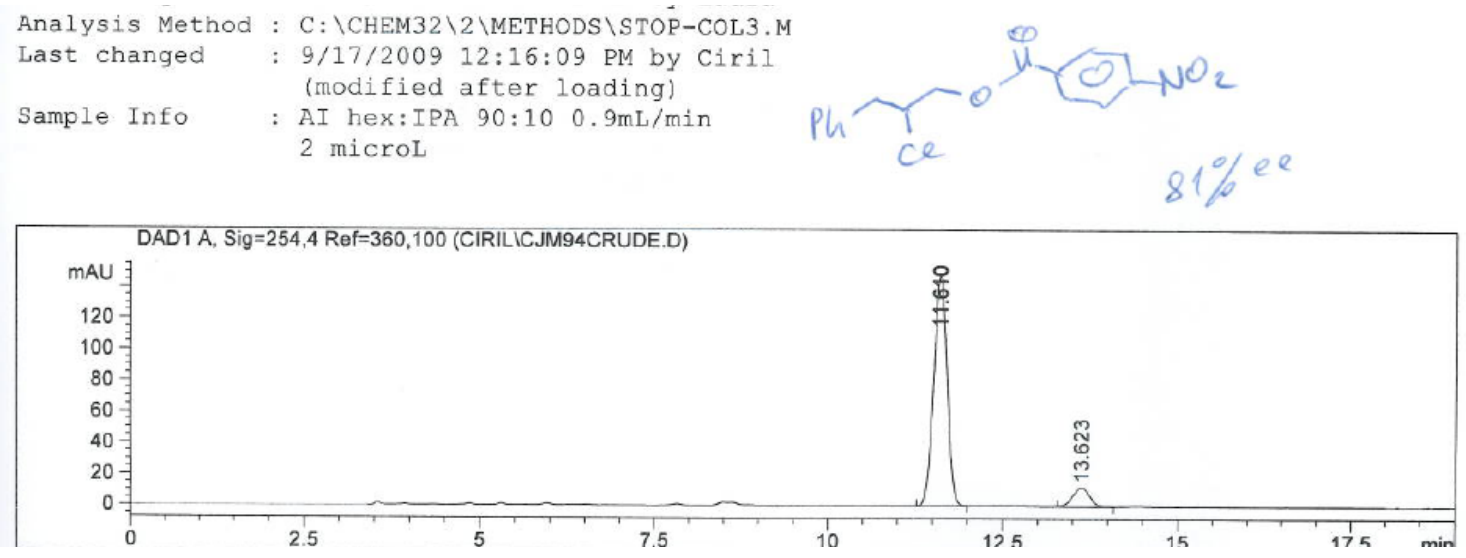
${ }^{1} \mathrm{H}$-NMR of the $p$-nitrobenzoate derivative of $\mathbf{3 a}$

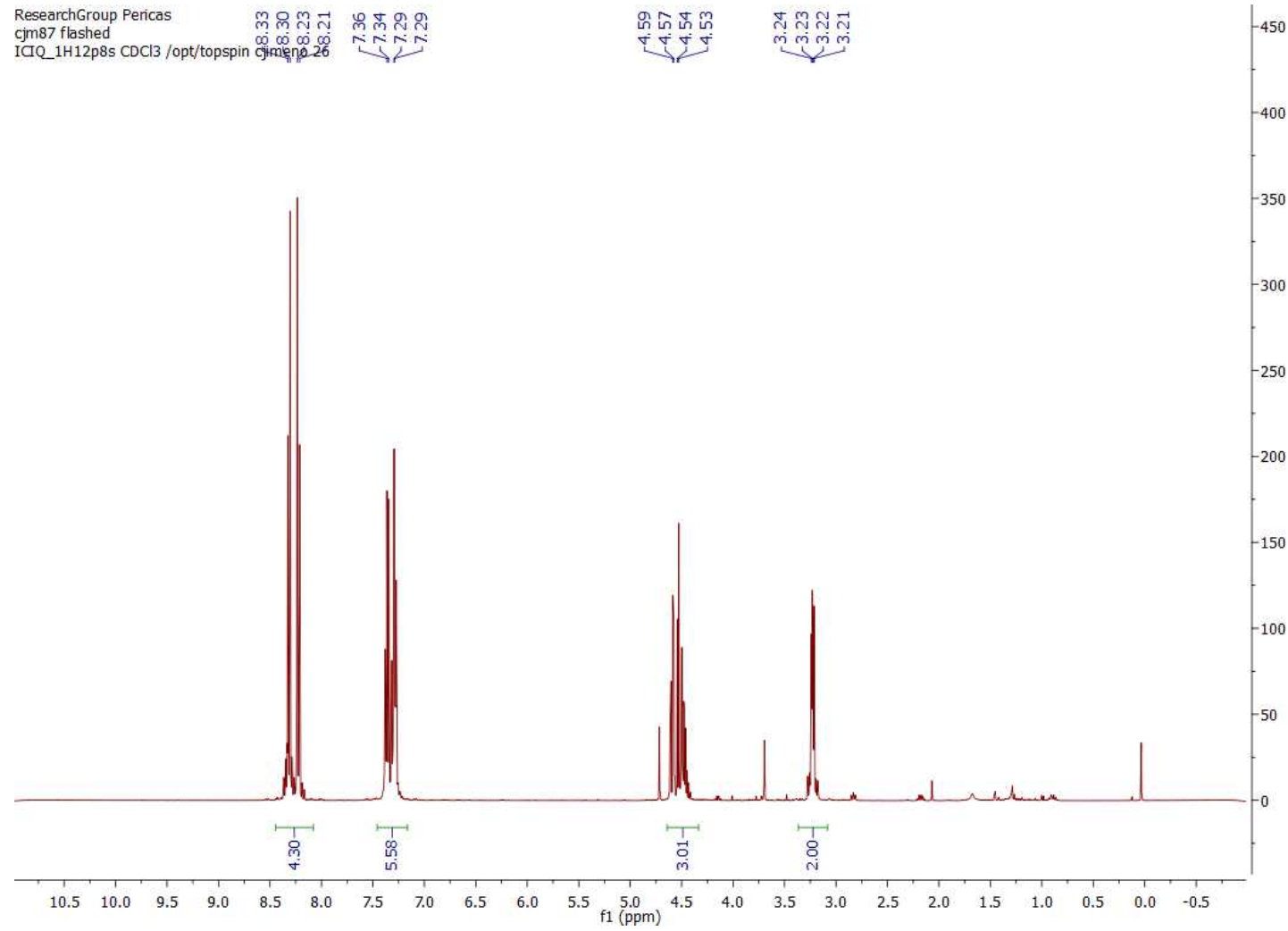

${ }^{13} \mathrm{C}$-NMR of the $p$-nitrobenzoate derivative of $\mathbf{3 a}$

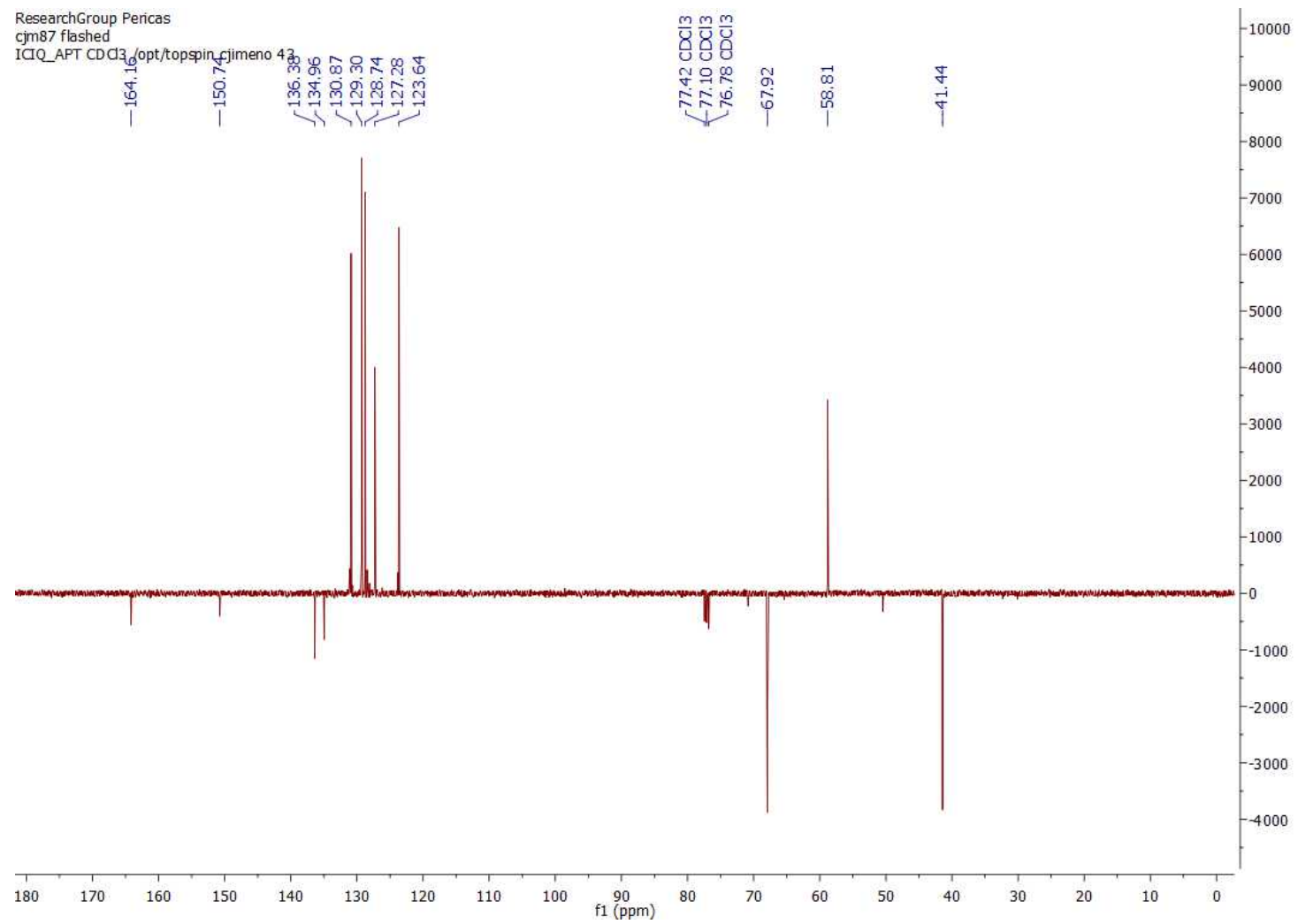




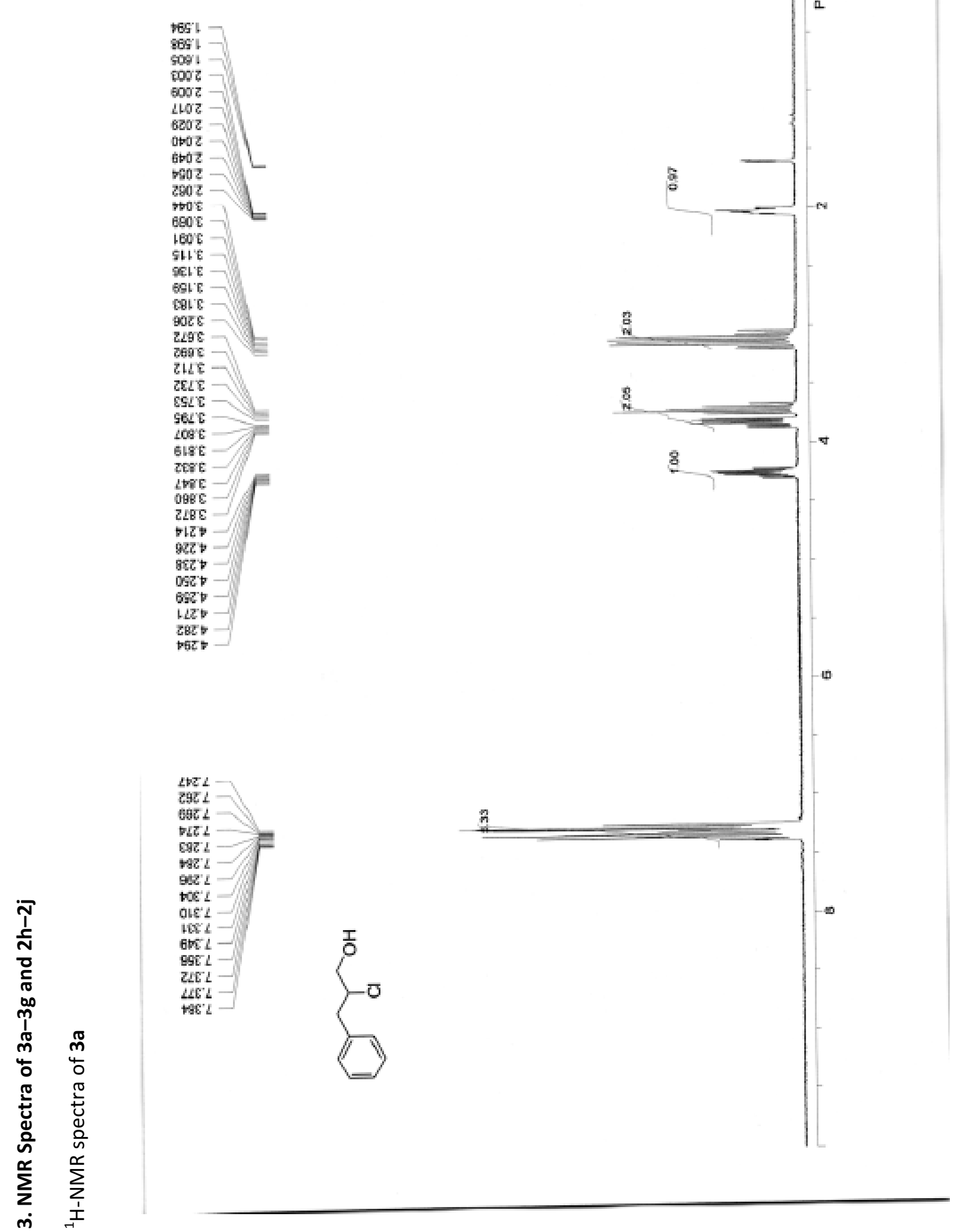


OsL 07

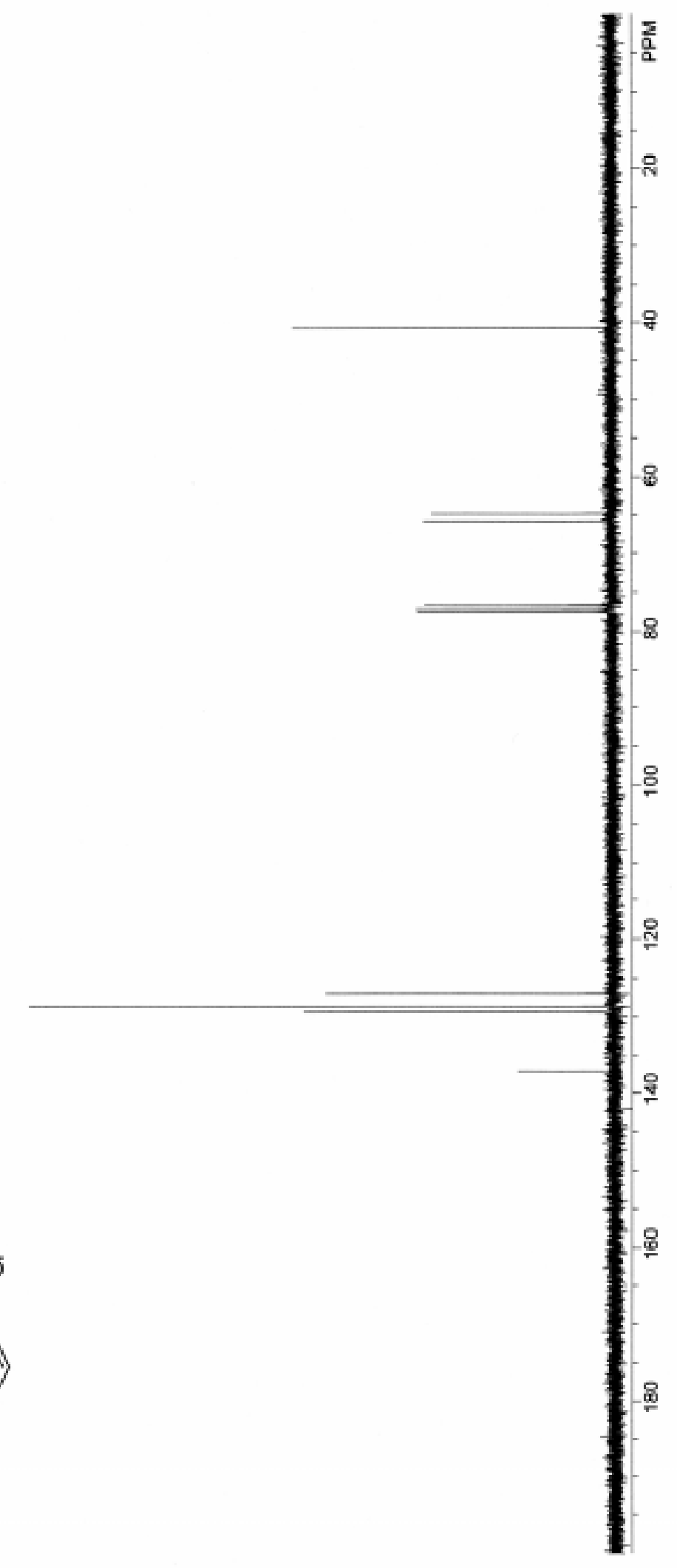

$8 \times 221$

20962

อZเ $2 \varepsilon$ เ

$\langle-0$

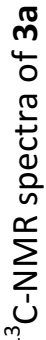

20699

62992
$6502 L$

690 


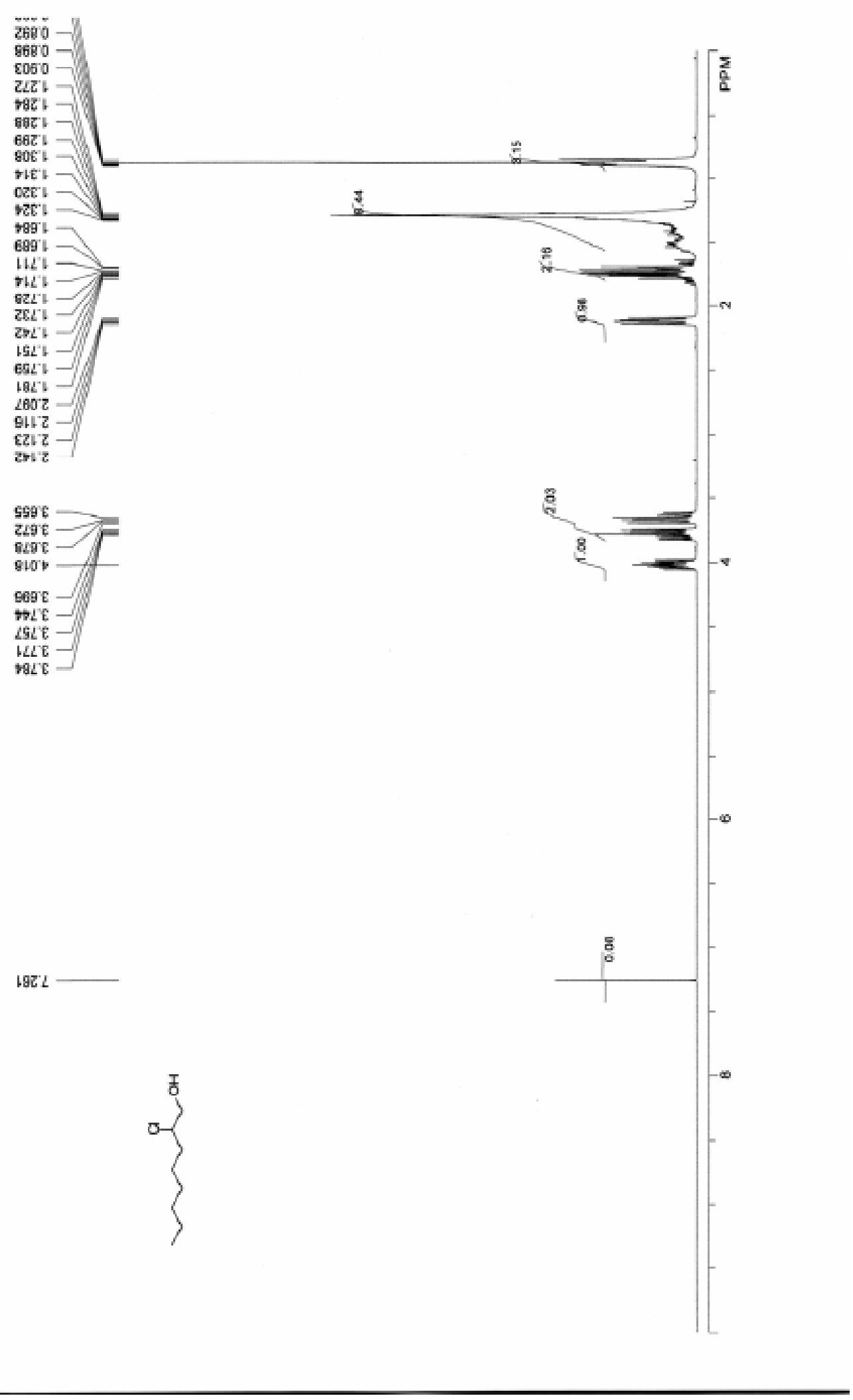


11

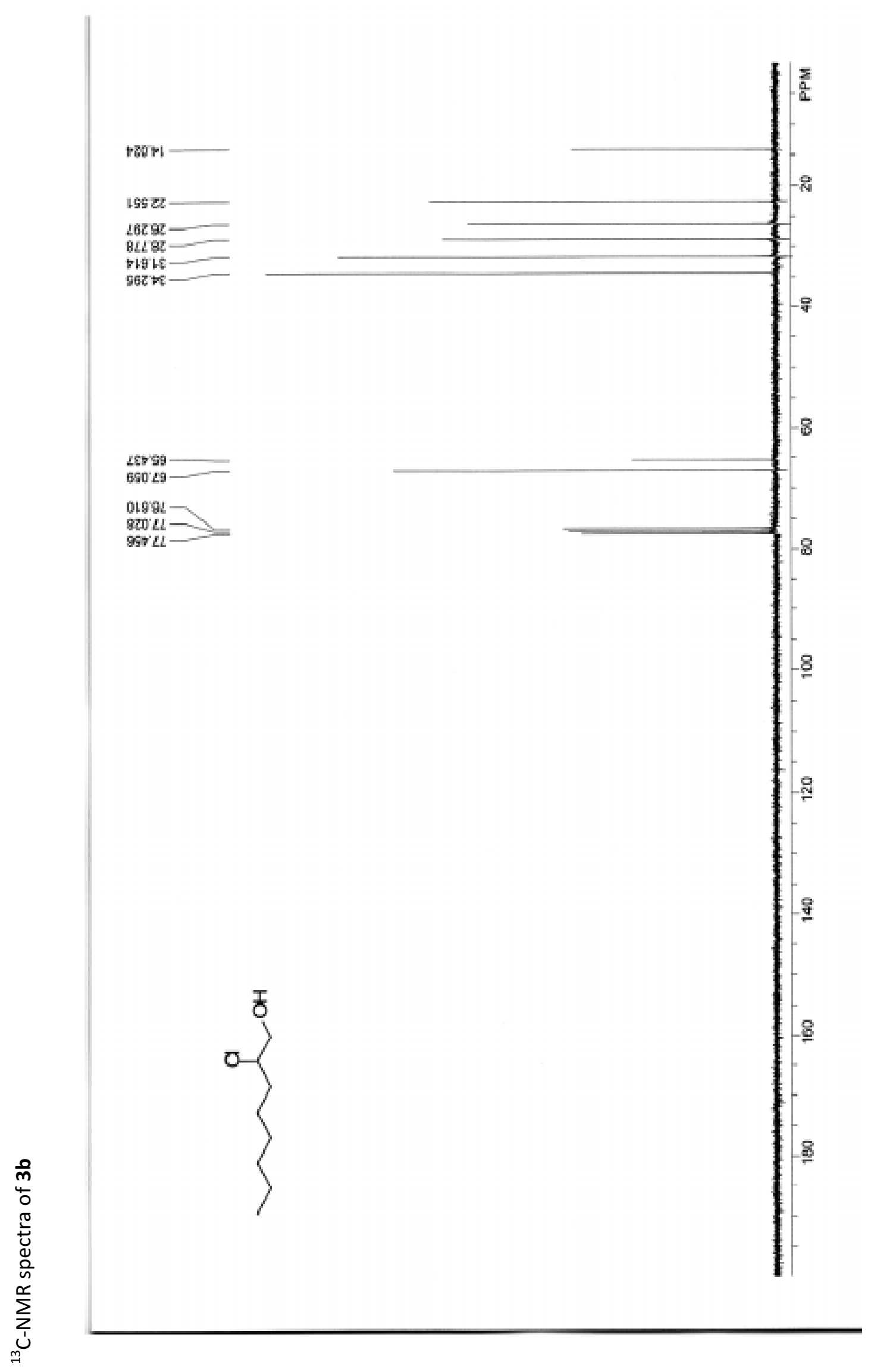



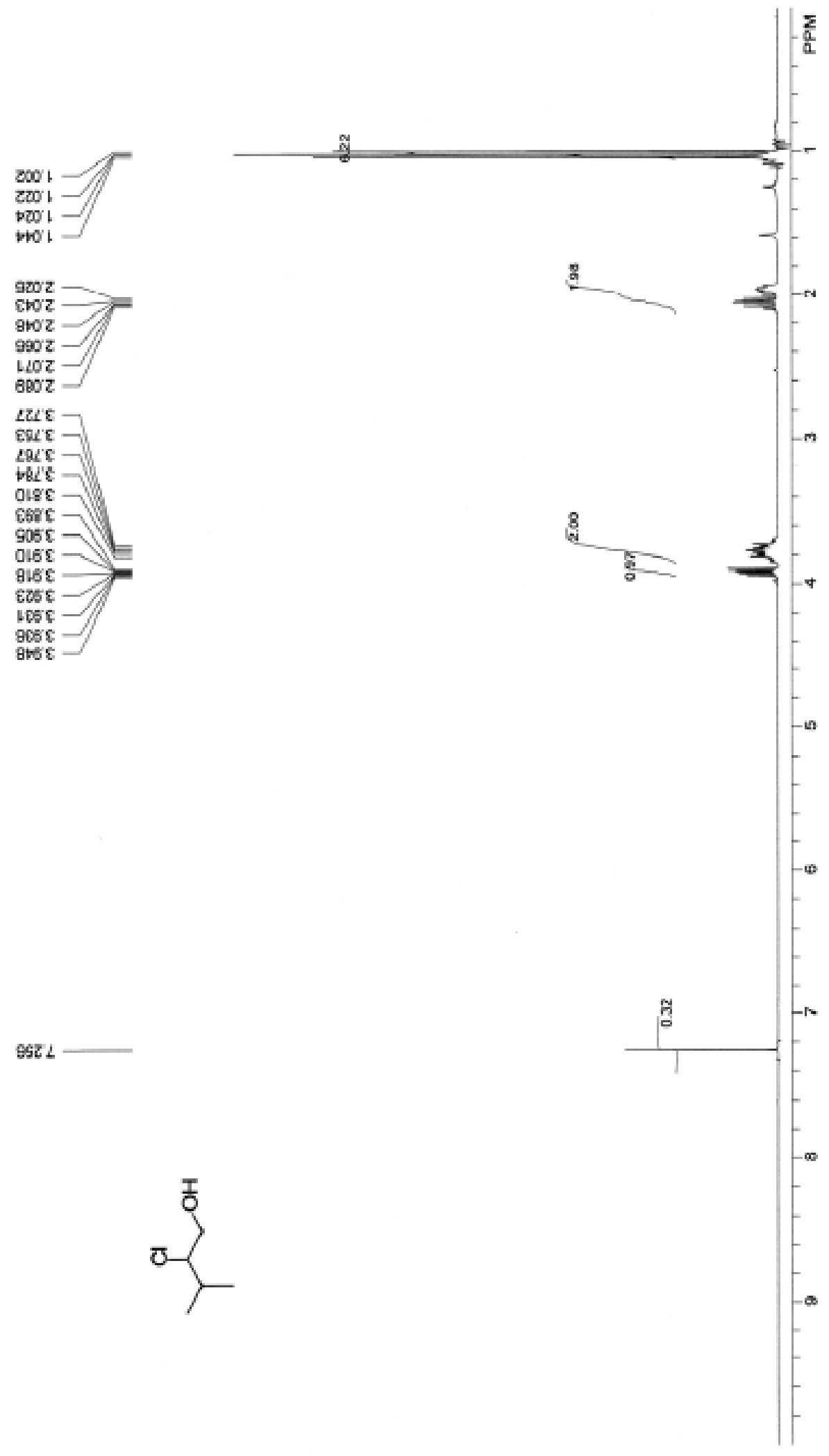

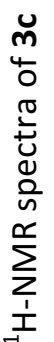

est 2<smiles>[2H]C(C[CH])C(C)C</smiles> 
13
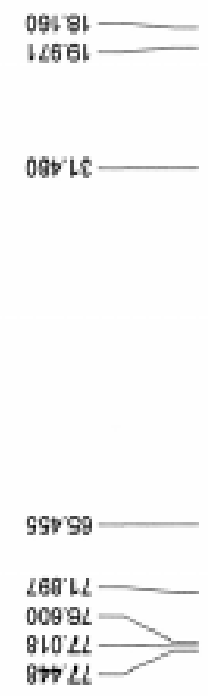<smiles>[2H]C(C[CH2-])C(C)C</smiles>

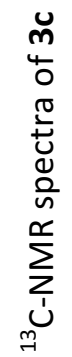

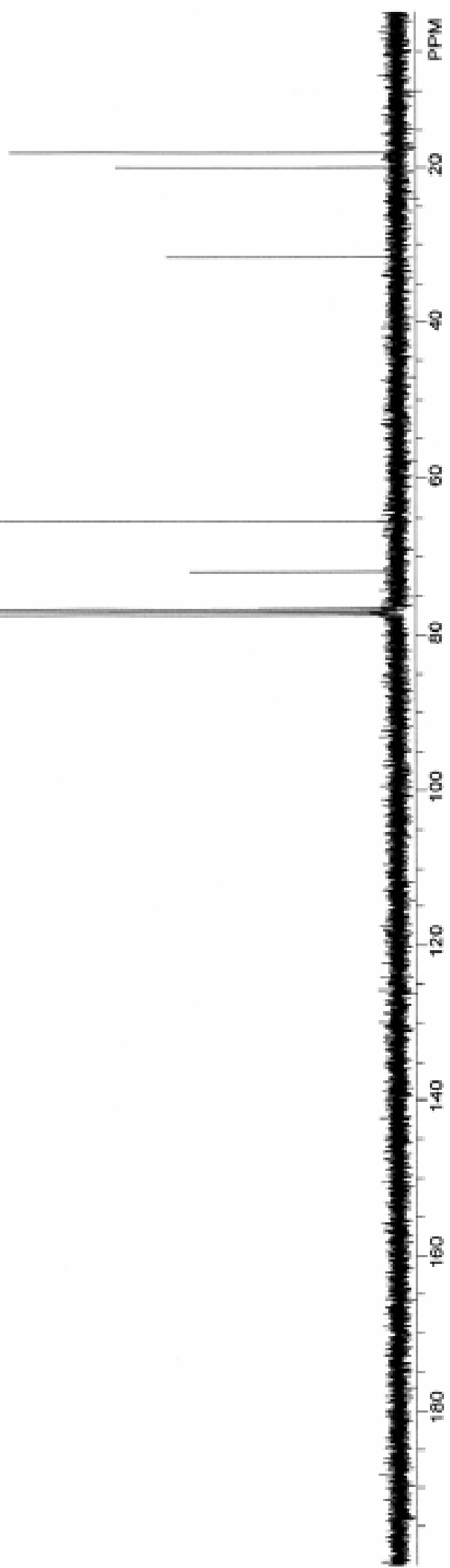




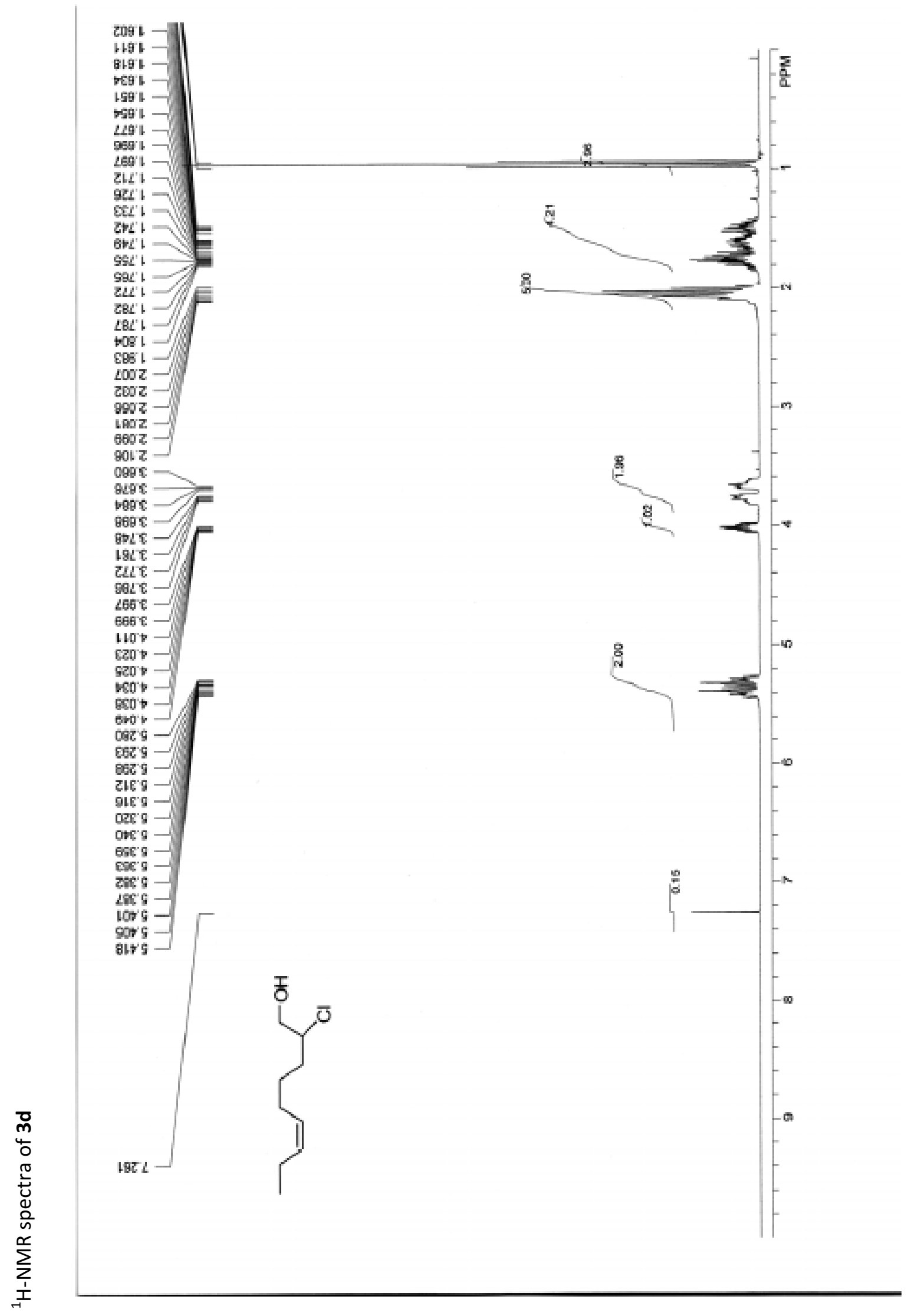




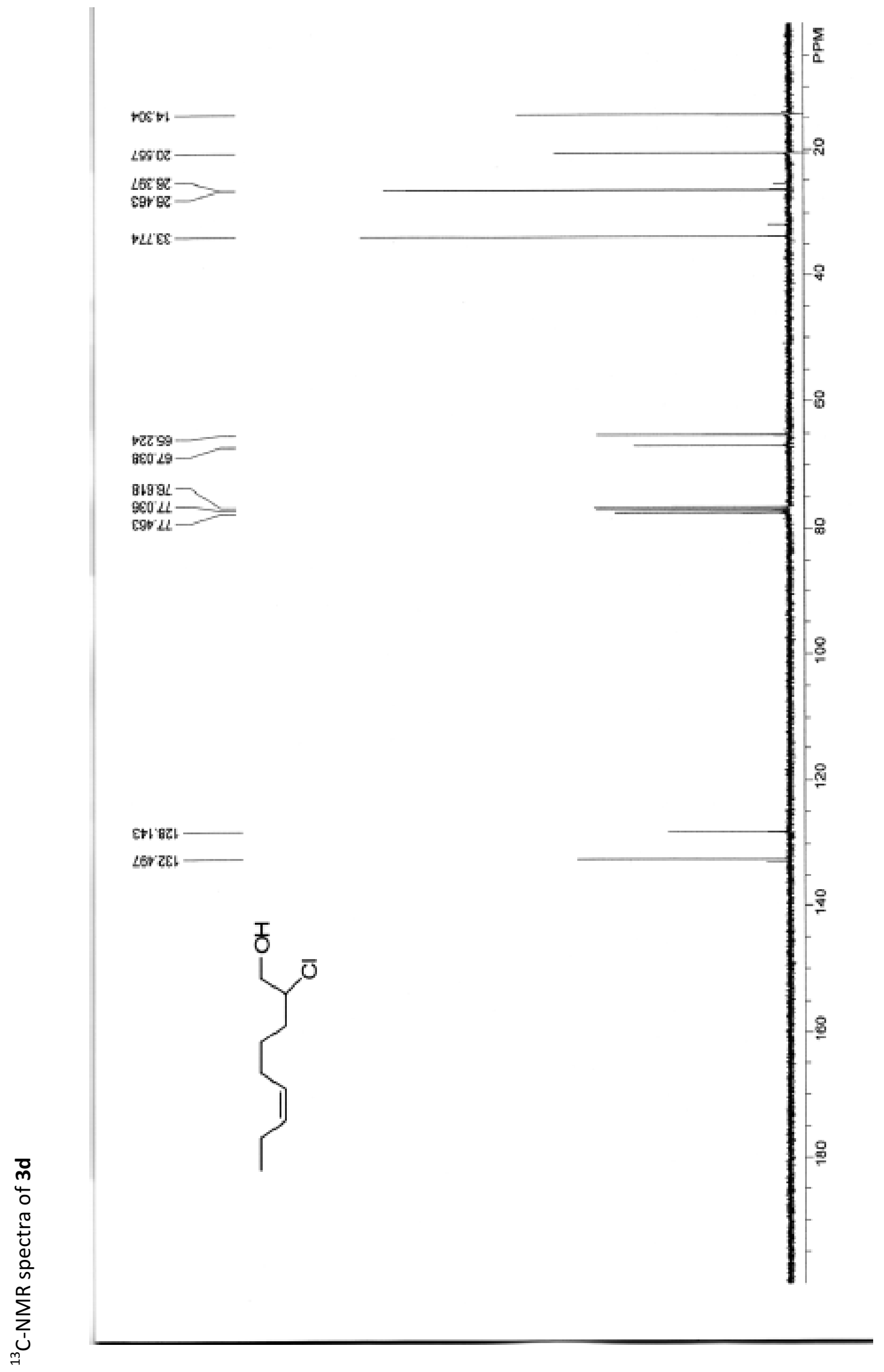




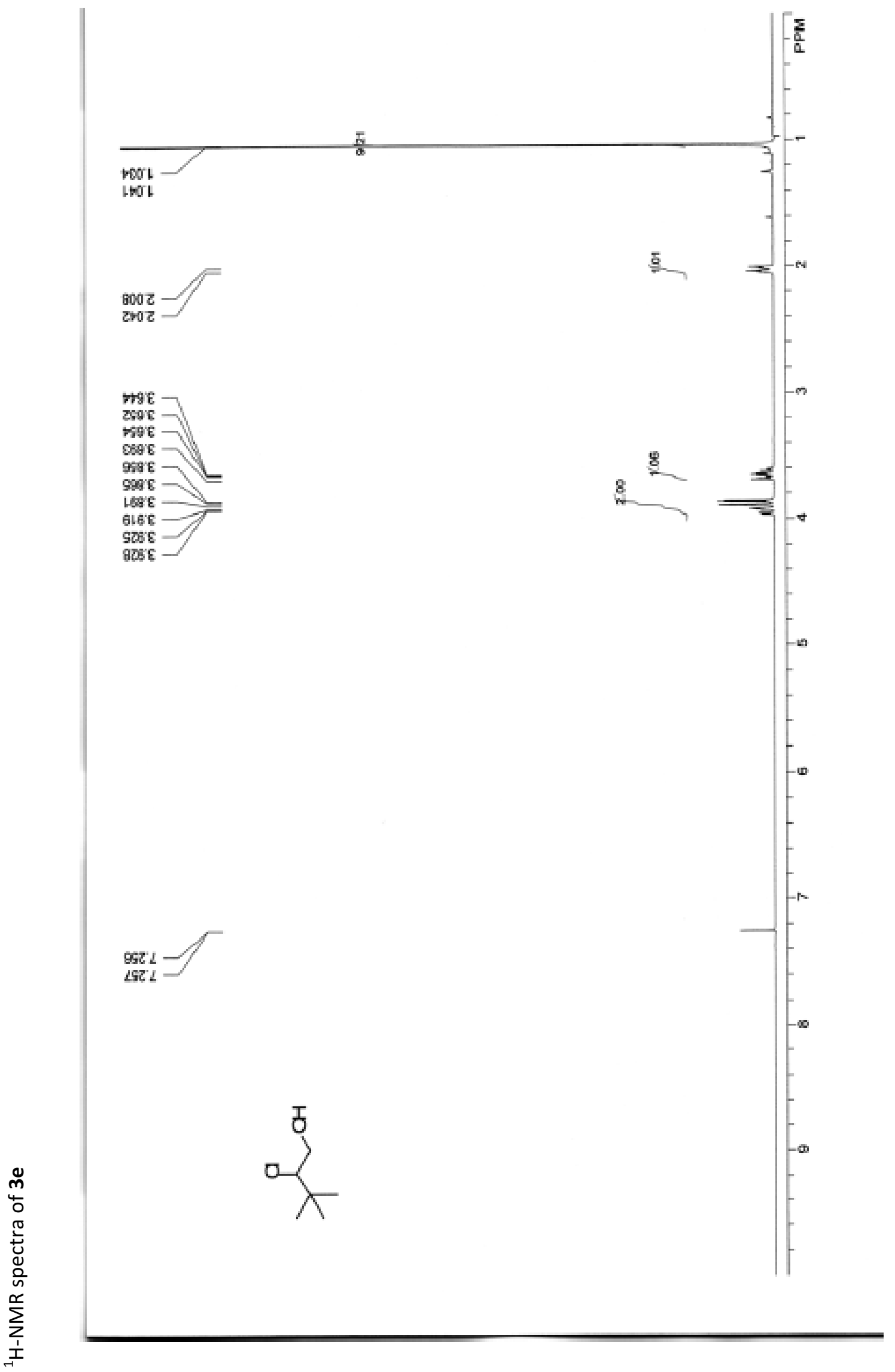




$$
\text { : }
$$




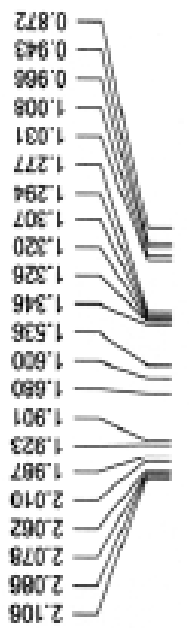

कac

$\csc 8-$

OLIE -

$2+0, b$

Eso -

590 -

clot -

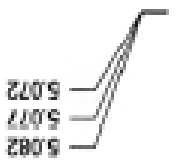
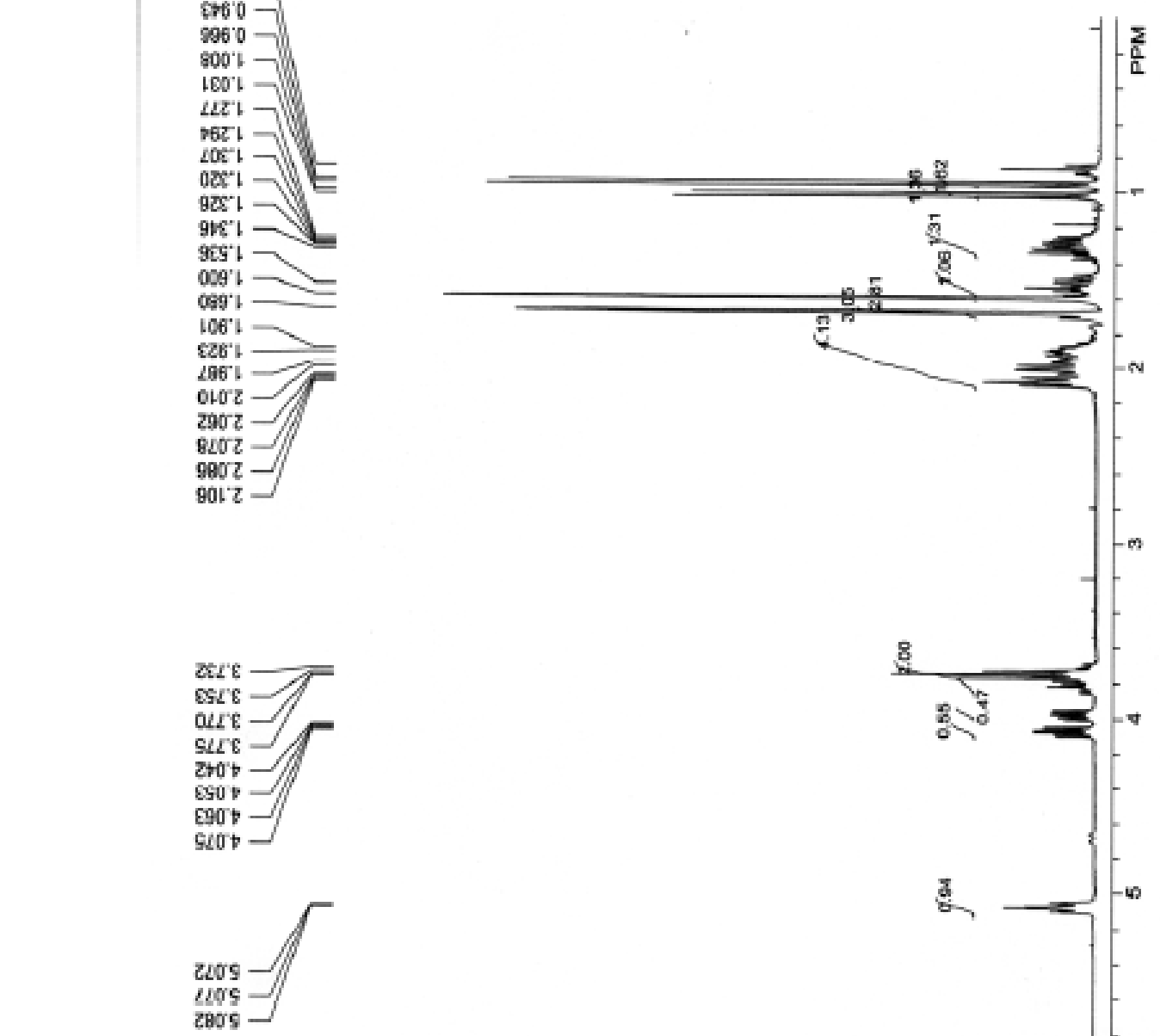

$\sqrt{8521}$

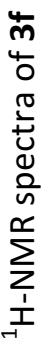
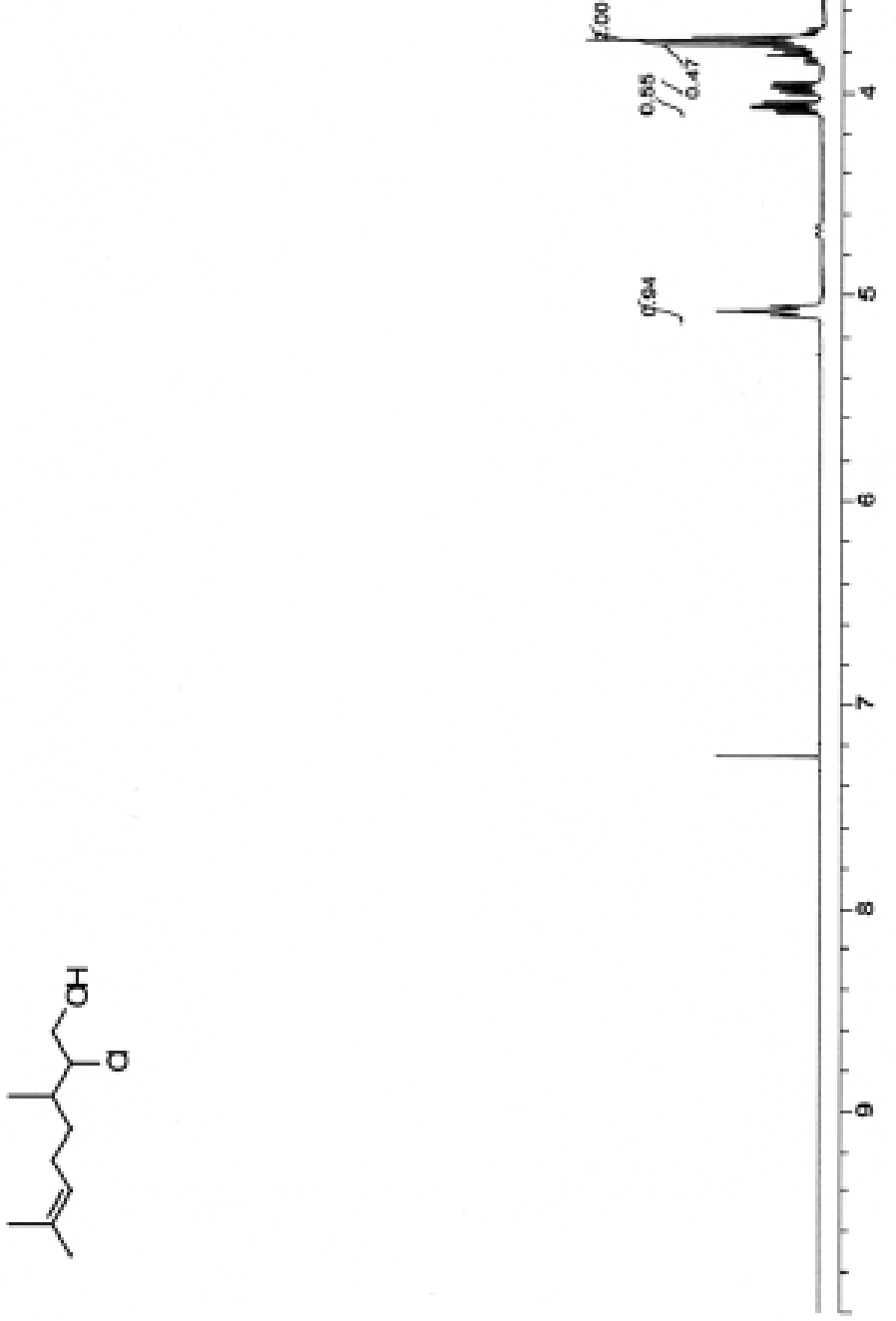


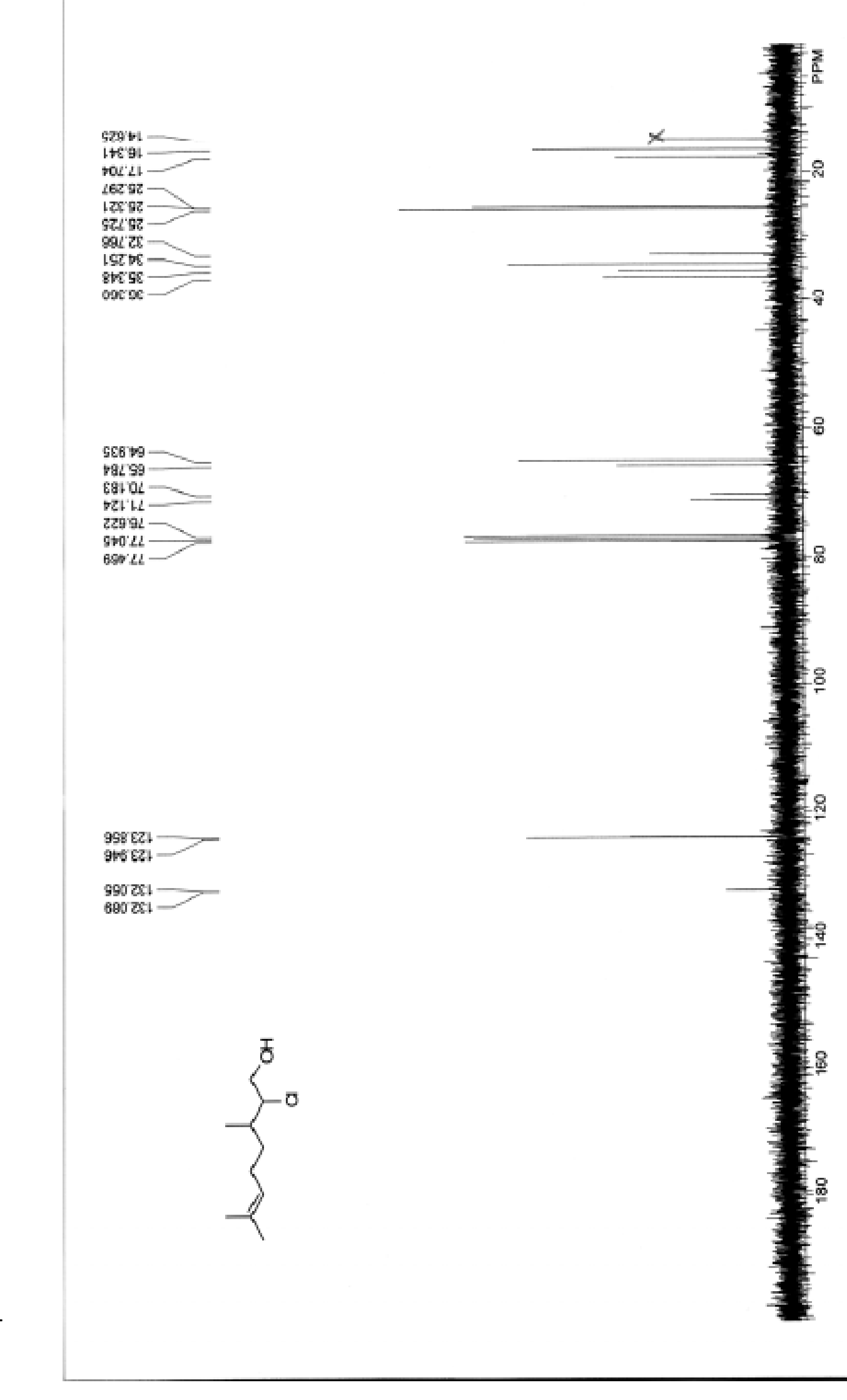


Eนเ

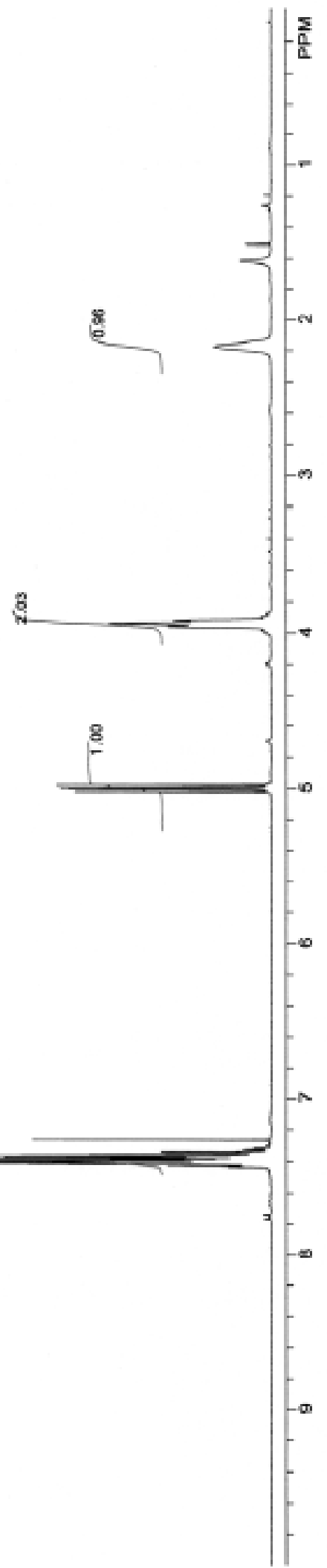

$\sum_{\substack{1 \\ j}}^{\infty}$
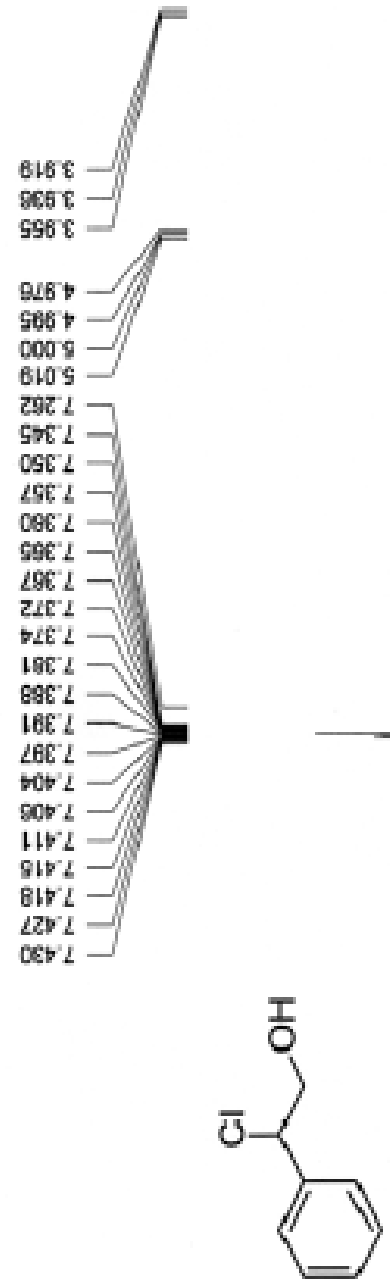

s 
LBเ $965<2$

s49 9

SW0'L

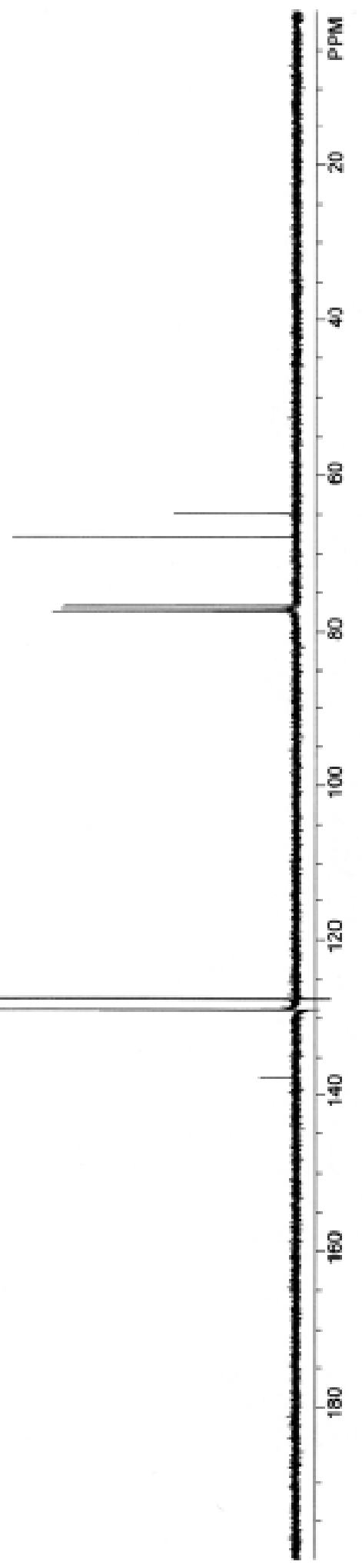

98t 221

cesez!
L1682!

$>8 E L E L$

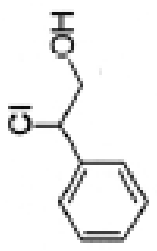


22

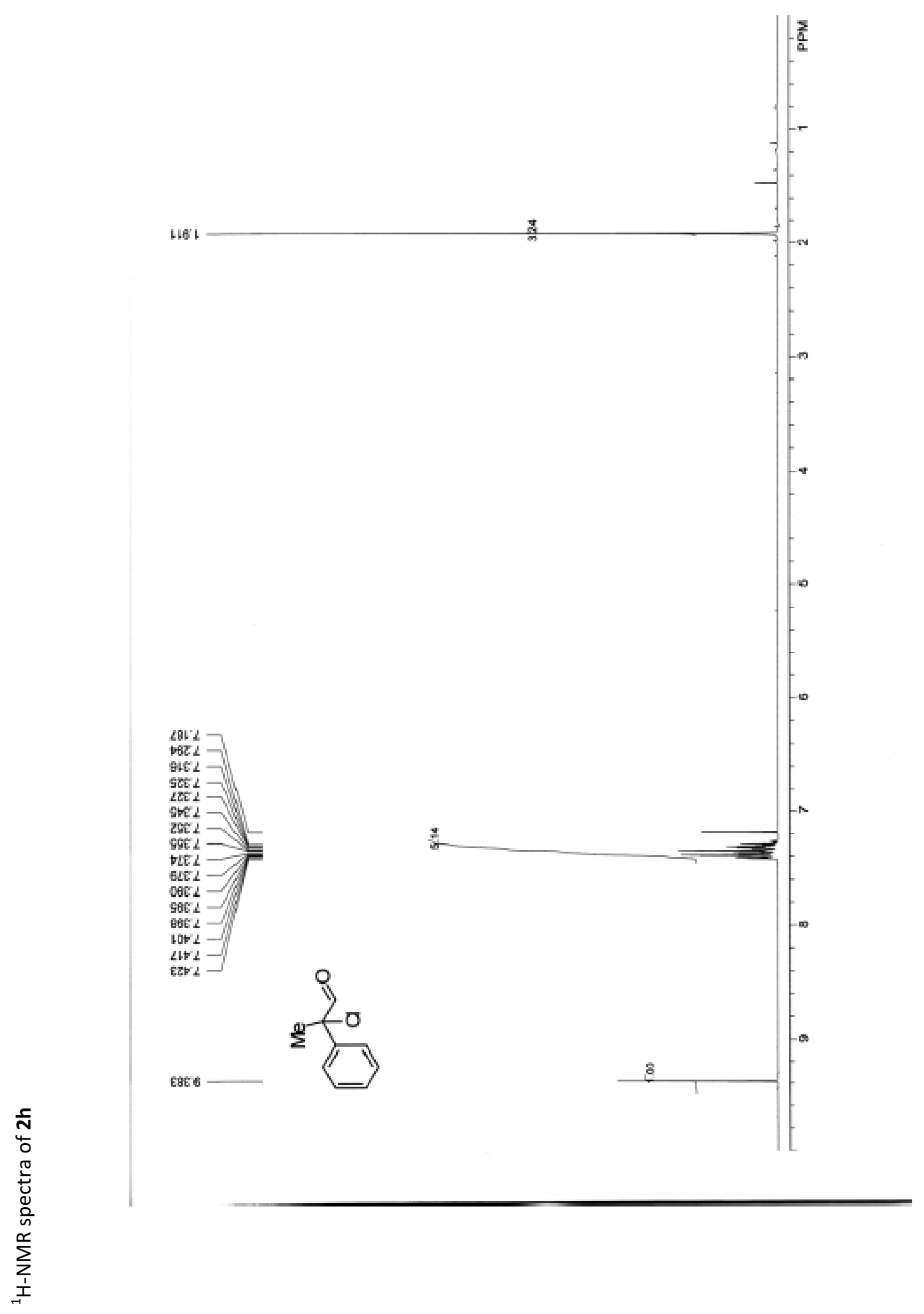


02552

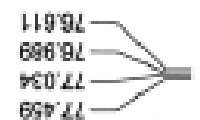

skl9zl-

$998921-\square$

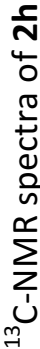

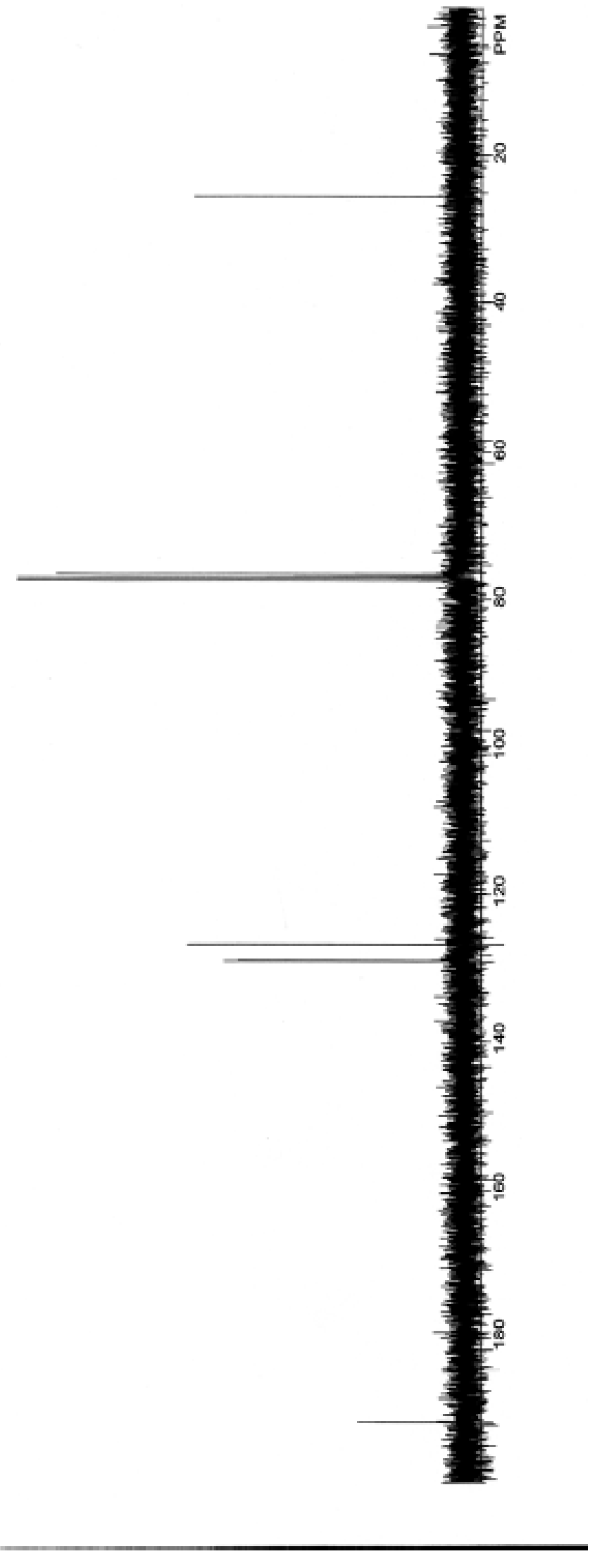

802161

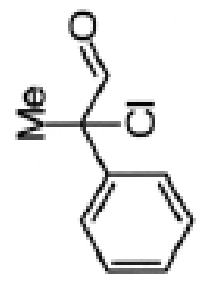


เ6Z!-

GLS!

685 '

$6 เ 9$ !

960

$90 \mathrm{C}$ : -

$9981-$

864

908 '

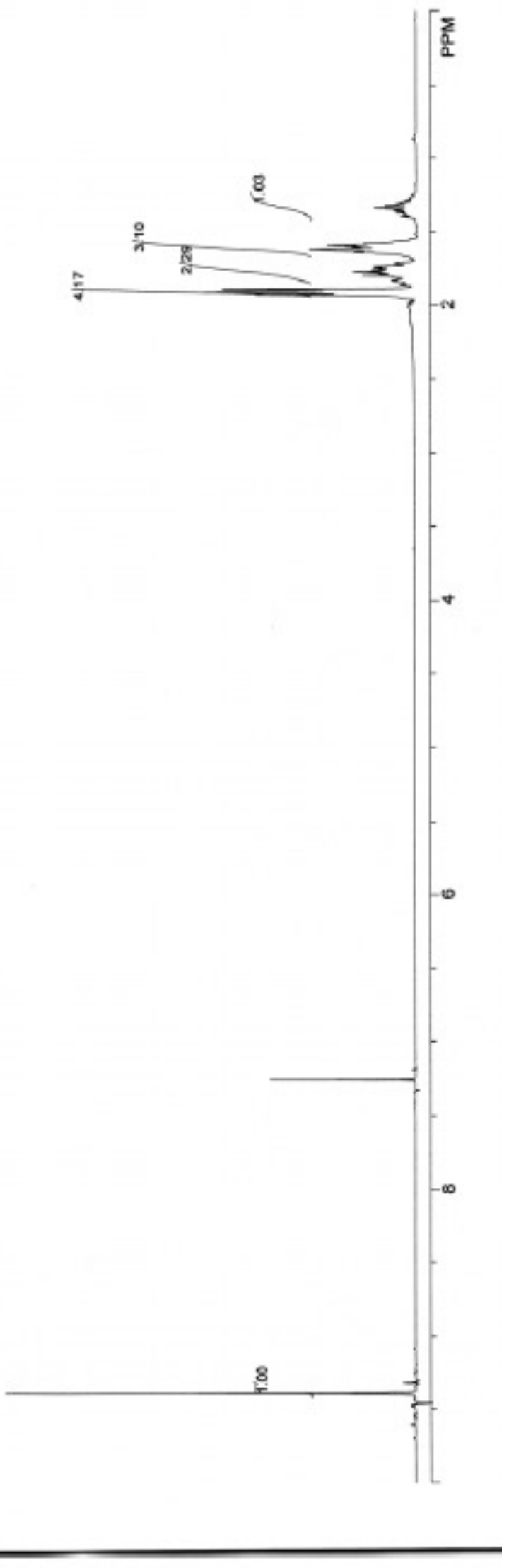




$$
1
$$


$\angle 580$

$098^{\circ} \longrightarrow$

cอ?!

9251.

ogs'

IQI -

489

0002

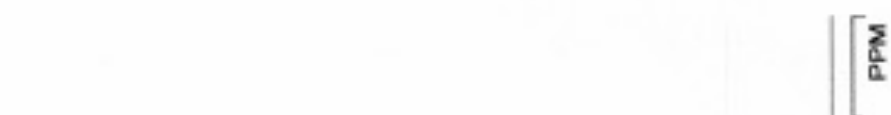

ह

$\equiv$

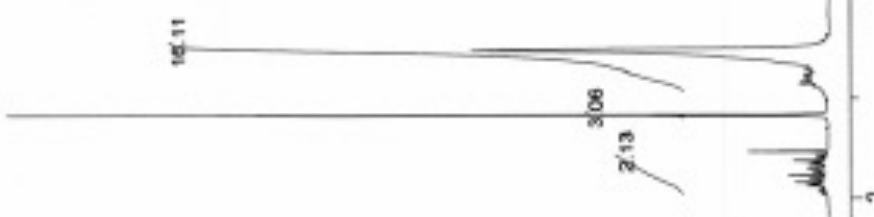

ISE L
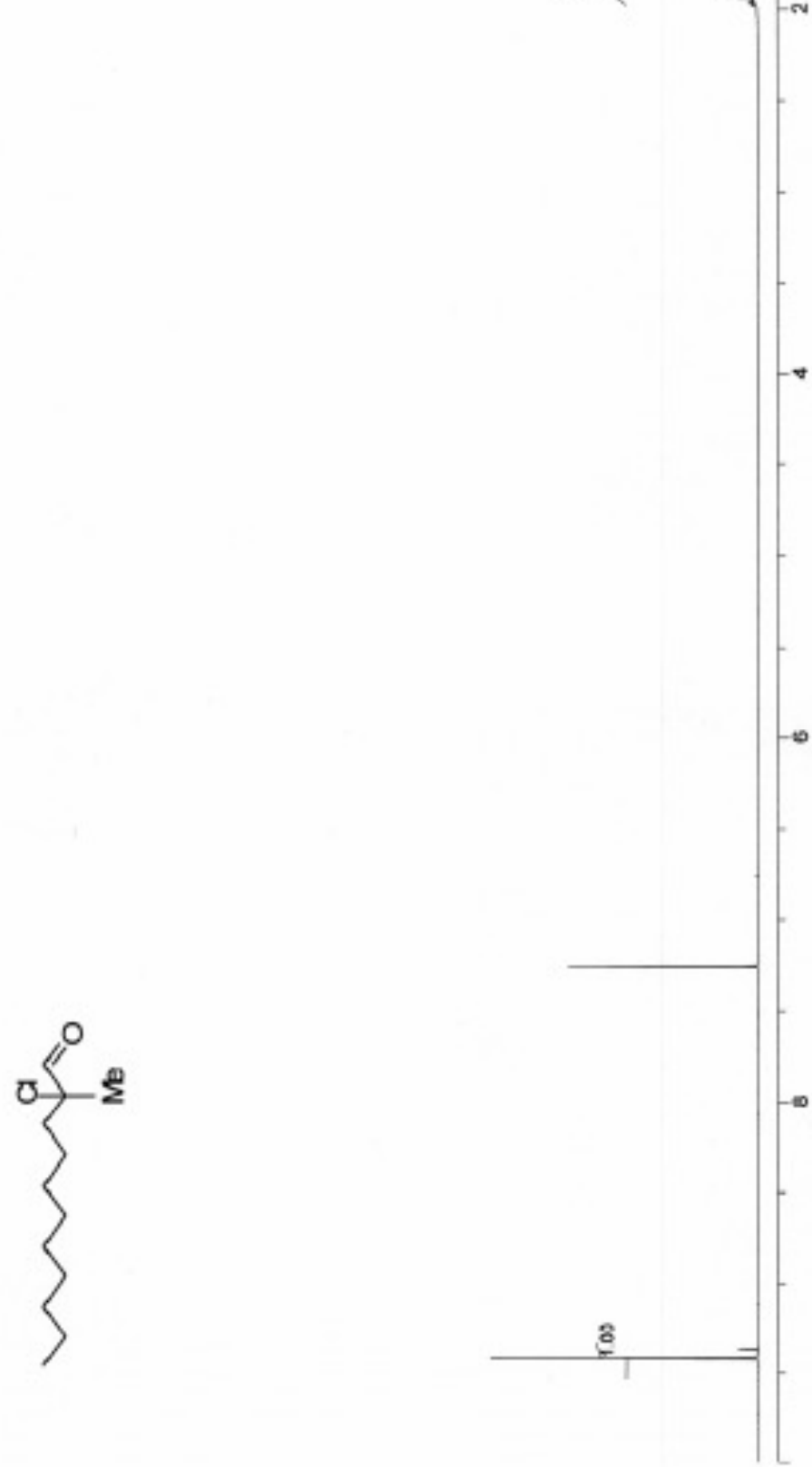


$$
1
$$

